\title{
Patterns of variability in early life traits of a Mediterranean coastal fish
}

\author{
Antonio Di Franco ${ }^{1,2, *, * *}$, Kaicheng Qian ${ }^{1, * *}$, Antonio Calò ${ }^{1}$, Manfredi Di Lorenzo ${ }^{1}$, \\ Serge Planes ${ }^{3,4}$, Paolo Guidetti ${ }^{1,2}$ \\ ${ }^{1}$ Laboratory of Conservation and Management of Marine and Coastal Resources, DiSTeBA, University of Salento, CoNISMa, \\ 73100 Lecce, Italy \\ ${ }^{2}$ Université de Nice Sophia-Antipolis, Faculté des Sciences, EA 4228 ECOMERS, 06108 Nice Cedex 2, France \\ ${ }^{3}$ USR 3278 CNRS-EPHE, ${ }^{4}$ Laboratoire d'excellence 'CORAIL', Centre de Recherches Insulaires et Observatoire de l'Environnement, \\ Université de Perpignan, 66860 Perpignan Cedex, France
}

\begin{abstract}
Spawning dates and pelagic larval duration (PLD) are early life traits (ELT) crucial for understanding life cycles, properly assessing patterns of connectivity and gathering indications about patchiness or homogeneity of larval pools. Considering that little attention has been paid to spatial variability in these traits, we investigated variability of ELT from the analysis of otolith microstructure in the common two-banded sea bream Diplodus vulgaris. In the southwestern Adriatic Sea, along $\sim 200 \mathrm{~km}$ of coast $\left(\sim 1^{\circ}\right.$ in latitude, $41.2^{\circ}$ to $\left.40.2^{\circ} \mathrm{N}\right)$, variability of ELT was assessed at multiple spatial scales. Overall, PLD (ranging from 25 to $61 \mathrm{~d}$ ) and spawning dates (October 2009 to February 2010) showed significant variability at small scales (i.e. $<6 \mathrm{~km}$ ), but not at larger scales. These outcomes suggest patchiness of the larval pool at small spatial scales. Multiple causal processes underlying the observed variability are discussed, along with the need to properly consider spatial variability in ELT, for example when delineating patterns of connectivity.
\end{abstract}

KEY WORDS: Life history traits $\cdot$ Spatial variability $\cdot$ Sea bream $\cdot$ Mediterranean Sea $\cdot$ Larval patchiness $\cdot$ Connectivity

\section{INTRODUCTION}

Most coastal fishes have bipartite life cycles, composed of a drifting planktonic phase (eggs and larval stages) and a relatively sedentary phase (postsettlers to adults, Thresher et al. 1989). During spawning (whose onset at species level has been related to environmental features, mainly water temperature, Vinagre et al. 2009) gametes are released. After fertilization, larvae hatch from the eggs. The larval stage lasts until the pelagic larva metamorphes into the benthic juvenile. Metamorphosis usually coincides with the transition-stage termed 'settlement' (Searcy \& Sponaugle 2000).
The pelagic larval duration (hereinafter PLD) corresponds to the period between spawning and settlement and is expressed in number of days (see Thresher et al. 1989). PLD and subsequent backcalculated spawning date can be assessed through the analysis of daily growth increments on otoliths (Pannella 1971, Searcy \& Sponaugle 2000). Otoliths develop around a primordium that is formed during the embryonic development and grow by apposition of daily increments. PLD, therefore, can be accurately assessed by counting the number of daily rings between the primordium and the settlement mark (i.e. the first major transitional point; for details about otolith microstructure see Panfili et al. 2002, Green et 
al. 2009). Spawning date is back-calculated, usually in recently settled specimens, by combining information on PLD and post-settlement age (i.e. the number of days the specimen lived after the settlement) with information on sampling date (see Di Franco \& Guidetti 2011, Di Franco et al. 2011).

Early life traits (hereinafter ELT), like e.g. PLD and spawning date, have been proven to be crucial features in improving our understanding of processes potentially affecting settlement and subsequent life stages (Williams 1983, Fontes et al. 2011). There is widespread belief that year-class strength in fish was determined from the success of the larval stage (Leggett \& DeBlois 1994). According to the 'criticalperiod' and the 'stage-duration' hypotheses, spawning date and PLD are key parameters in shaping settlement and recruitment (the phase when juvenile fish join the adult fraction of populations) success, because larval history and ELTs of settlers influence individual fitness in subsequent life stages (Searcy \& Sponaugle 2000, Vigliola \& Meekan 2002, Hamilton et al. 2008).

Besides the significance of ELTs in affecting settlement and subsequent life stages discussed above, information on PLD and spawning date is also necessary to model larval dispersal (Watson et al. 2010). In order to properly simulate patterns of dispersal and connectivity in specific regions or for different species and populations (see Kettle \& Haines 2006, Waston et al. 2010), biophysical models need to be fed with data on key physical dynamics and biological traits (like spawning date and PLD). In fact, coupling physical and biological features into so-called biophysical model-based studies (e.g. Lagrangian models) appears to be the most effective approach for elucidating patterns of connectivity for different marine species (Siegel et al. 2003, Werner et al. 2007, Watson et al. 2010). Connectivity, defined as the demographic linking of local populations through the dispersal among them of individuals as eggs, larvae, juveniles, subadults or adults, is still a relatively little known phenomenon in many regions and for many species (Sale et al. 2005). However, its importance, for example in designing effective networks of marine protected areas, has been increasingly recognized (Palumbi 2003, Sale et al. 2005, Almany et al. 2009, Jones et al. 2009, McCook et al. 2009, SaenzAgudelo et al. 2011). From this point of view, there is usually a potential bias in the application of biophysical modeling as accurate PLD estimates are seldom available. Many studies, in fact, are based on values of PLD generally estimated in a single place or in a specific year, de facto neglecting the potential variability of this ELT (Di Franco \& Guidetti 2011, Di
Franco et al. 2011) and providing, potentially inappropriate generalizations about patterns of connectivity (i.e. based on ELTs investigated elsewhere or in different years).

This lack of information is particularly surprising considering that larvae occur in patches, potentially due to both passive accumulation of larvae or active aggregation (Kingsford \& Choat 1989, Williams \& English 1992, Paris \& Cowen 2004) and, from this perspective, they potentially face different environmental conditions putatively causing spatial differences in ELTs (Sponaugle et al. 2006).

For all the above reasons, it is necessary to gain further information regarding ELTs and their potential spatial variability. Recent studies have shown that both PLD and spawning date can be variable at a relatively small spatial scale (Di Franco \& Guidetti 2011, Kingsford et al. 2011). However, due to the pioneering nature of these studies and the limited number of species studied so far, it is not possible to draw any general conclusion.

Following the general approach as described by Di Franco \& Guidetti (2011), we presently aim at investigating patterns of variability of PLD and spawning dates of the common two-banded sea bream Diplodus vulgaris (Saint-Hilaire 1817) at multiple spatial scales along the SE coast of Italy (SW Adriatic Sea). Our study shall provide: (1) indication of local patchiness (i.e. in case of variability of ELTs) or homogeneity (i.e. in case of absence of variability) of larval pools; (2) proper tools to further investigate processes potentially affecting settlement and subsequent life stages and then adequately model patterns of dispersal and connectivity.

\section{MATERIALS AND METHODS}

As a model species we used the two-banded sea bream Diplodus vulgaris, a commercially and ecologically relevant coastal fish (Guidetti 2006) distributed throughout the Mediterranean and along the eastern Atlantic coast (from $\sim 48^{\circ}$ to $14^{\circ} \mathrm{N}$, Bauchot \& Hureau 1986). The species is among the most targeted fishes for recreational fishing in the Mediterranean (Lloret et al. 2008).

Juvenile Diplodus vulgaris were collected in May 2010, along $\sim 200 \mathrm{~km}$ of the Apulian Adriatic coast, in line with a north-south axis $\left(\sim 1^{\circ}\right.$, from $41.2^{\circ} \mathrm{N}$ to $40.2^{\circ} \mathrm{N}_{i}$ Fig. 1). Seven areas of the coast, separated by 15 to $30 \mathrm{~km}$ each, were used as sampling locations (each corresponding to $\sim 6 \mathrm{~km}$ of coastline). Within each location, 2 sites (each $\sim 100$ to $200 \mathrm{~m}$ of coastline 


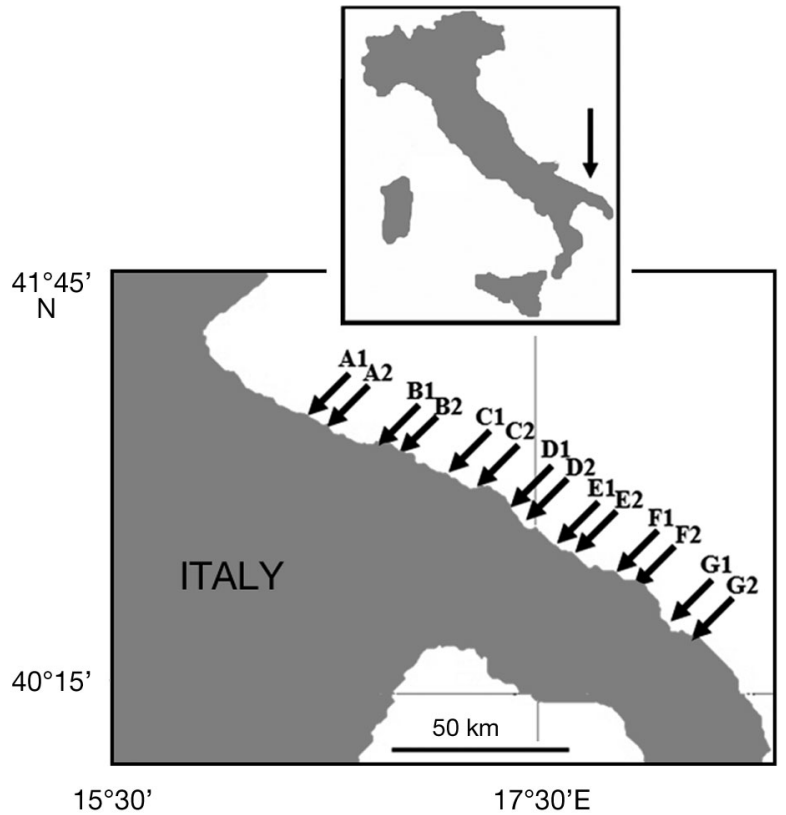

Fig. 1. Sampling locations (letters) and sites (numbers), respectively: $\mathrm{A} 1=$ San Giorgio, $\mathrm{A} 2=$ Torre a Mare; $\mathrm{B} 1=$ Cala Corvina, B2 = Porto Marzano; C1 = Hotel La Darsena, C2 Torre Pozzella; D1 = Punta Penna Grossa, D2 = Terza Baia; E1 = Torre Rossa, E2 = Punta Penne; F1 = Casalabate, F2 = Torre Rinalda; G1 = San Foca, G2 = San Andrea

and separated by 2 to $6 \mathrm{~km}$ ) were randomly selected. A hand-net was used to collect 10 to 12 post-settlers per site (for a total of $\mathrm{n}=160$ ). The number of postsettlers within each site was set up in accordance with recent papers dealing with spatial variability of ELT (Di Franco \& Guidetti 2011, Di Franco et al. 2011, Kingsford et al. 2011).

Across locations, all specimens were collected within $10 \mathrm{~d}$ to prevent or at least reduce temporal bias and frozen after capture. Settlers of two-banded sea breams usually aggregate into discrete schools (Harmelin Vivien et al. 1995), reflecting different settlement pulses, each potentially differing in ELTs. The abundance of juveniles at our study sites was so high that it was often impossible to detect significant discontinuity in juvenile fish distribution. In any case, in order to prevent the potential confounding between inter-site variability with intra-site variability (i.e. potentially related to different pulses), we randomly collected juvenile individuals (10 to 12 per site) along 100 to $200 \mathrm{~m}$ of coastline at each site. Sampling was carried out 1 to 5 mo after the start of the settlement period (see results section) in order to (1) include post-settlers derived from multiple settlement pulses and not just from the early ones; (2) focus on successful post-settlers (the ones that survived the high early-mortality rates, Searcy \& Sponaugle 2001), these being the ones that more effectively contribute to replenishing local populations.

Standard otolith aging by analysis of daily microincrement formation (growth rings) (Victor 1982, Philibotte 2002, Di Franco \& Guidetti 2011, Di Franco et al. 2011) was used to determine PLD and spawning date.

The daily deposition of growth rings on sagittae of Diplodus vulgaris has been validated by both Villanueva \& Moli (1997) and Vigliola (1997). Therefore, we assumed that increments were deposited on a daily periodicity from the first one formed at hatching (Tsuji \& Aoyama 1982) until the one formed on the day the fish was sampled. Vigliola et al. (2000) detected an abrupt decline in the width of successive increments that appeared to coincide with settlement of $D$. vulgaris. This description fits the criteria of the type I settlement mark (i.e. corresponding to the settlement of the planktonic larva metamorphosing into the benthic juvenile) classified according to Wilson \& McCormick (1997) and will be used as reference to locate the settlement mark in $D$. vulgaris otoliths in the present study. By applying this 'type I settlement mark' to our samples, we have also assumed that the structure of settlement mark is consistent among individual D. vulgaris (Wilson \& McCormick 1997).

Before removing the otoliths, standard lengths (SL) of the collected juvenile Diplodus vulgaris were measured to the nearest $1 \mathrm{~mm}$. One sagittal otolith was removed from each specimen and processed following a standard procedure (see Di Franco \& Guidetti 2011, Di Franco et al. 2011). The daily rings were read using a microscope with magnification $400 \times$. For each specimen, the hatching date was back-calculated by subtracting the number of growth increments from the sampling date. The spawning date was then calculated by subtracting $2 \mathrm{~d}$ (corresponding to the time between spawning and hatching in D. vulgaris, Jug-Dujakovic \& Glamuzina 1988) from the previously estimated hatching date.

To test for spatial variability in PLD and spawning dates, analysis of covariance (ANCOVA) was run, where Location (Lo) was treated as a random factor with 7 levels, Site $(\mathrm{Si})$ was used as a random factor nested within Lo, with 2 levels, and Standard length (SL) as the covariate. Between 10 and 12 otoliths (replicates) were read from each site. The test for covariate effect was performed to prevent fish size (possibly different from site to site) effects on spatial comparisons of PLDs and spawning dates. In other words, only focusing on fish size, any observed difference is attributable to 'pure' spatial patterns. In order to run ANCOVA, the spawning date for each 
fish was converted into an integer between 0 (indicating 20 October 2009, first spawning date recorded, see Results) and 117 (indicating 14 February 2010, last spawning date recorded). Before performing ANCOVA, the data were tested for homogeneity of dispersion using Permutational Analysis of Multivariate Dispersions (PERMDISP) based on Euclidean distance, which is equivalent to Levene's test for heterogeneity of variances when used on univariate data (Anderson et al. 2008). No evidence of heterogeneity of variance was highlighted for PLD or for spawning date data ( $p>0.05$ for both tests).

Linear regression analysis (DISTLM, distancebased linear models) was used to assess the relationships between (1) the spawning date (converted in an integer as detailed above) and the PLD and (2) the SL and the spawning date at the individual level.

Statistical analyses were run using Primer 6 PERMANOVA + software package.

\section{RESULTS}

Fish size (SL) ranged from 15 to $30 \mathrm{~mm}$ (mean $\pm \mathrm{SE}$ $=25 \pm 0.2 \mathrm{~mm}$ ). SL per site (mean $\pm \mathrm{SE}$ ) varied from $19 \pm 0.5 \mathrm{~mm}$ to $23 \pm 0.8$ (Fig. 2a). Coefficient of variation for each site ranged from 0.05 to 0.13 . Post-settlement age ranged from 37 to $154 \mathrm{~d}$ (mean $\pm \mathrm{SE}=$ $93.5 \pm 1.6 \mathrm{~d}$ ). The post-settlement age per site (mean $\pm \mathrm{SE}$ ) varied from $73.7 \pm 5 \mathrm{~d}$ to $107.3 \pm 4 \mathrm{~d}$ (Fig. $2 \mathrm{~b}$ ).

PLD values ranged, on the whole, from 25 to $61 \mathrm{~d}$. $\mathrm{PLD}($ mean $\pm \mathrm{SE})$ per site varied from $35.8 \pm 1.3 \mathrm{~d}$ to $52.3 \pm 0.7 \mathrm{~d}$ (Fig. 2c). Coefficient of variation for each site ranged from 0.05 to 0.25 .

Spawning dates ranged from 20 October 2009 to 14 February 2010, covering 117 d in total (including the end date). More than $60 \%$ of spawning dates occurred in December 2009, with a frequency for each date in December ranging from $0.6 \%$ to $3.7 \%$ (Fig. 3a). Settlement dates ranged from 1 December 2009 to 28 March 2010, covering 118 d in total (including the end date). More than $45 \%$ of settlement dates occurred in January and $40 \%$ in February (Fig. 3b).

Results of ANCOVA test showed that both PLD and spawning dates varied significantly at the scale of sites (Si), whereas no significant differences were detected among locations (Lo). Significant effect of the covariate SL was detected on spawning dates, but not on PLD (Table 1). A negative relationship ( $\mathrm{p}<$ 0.01) between SL and spawning date was highlighted with larger juveniles that were spawned earlier than smaller ones (Fig. 4).
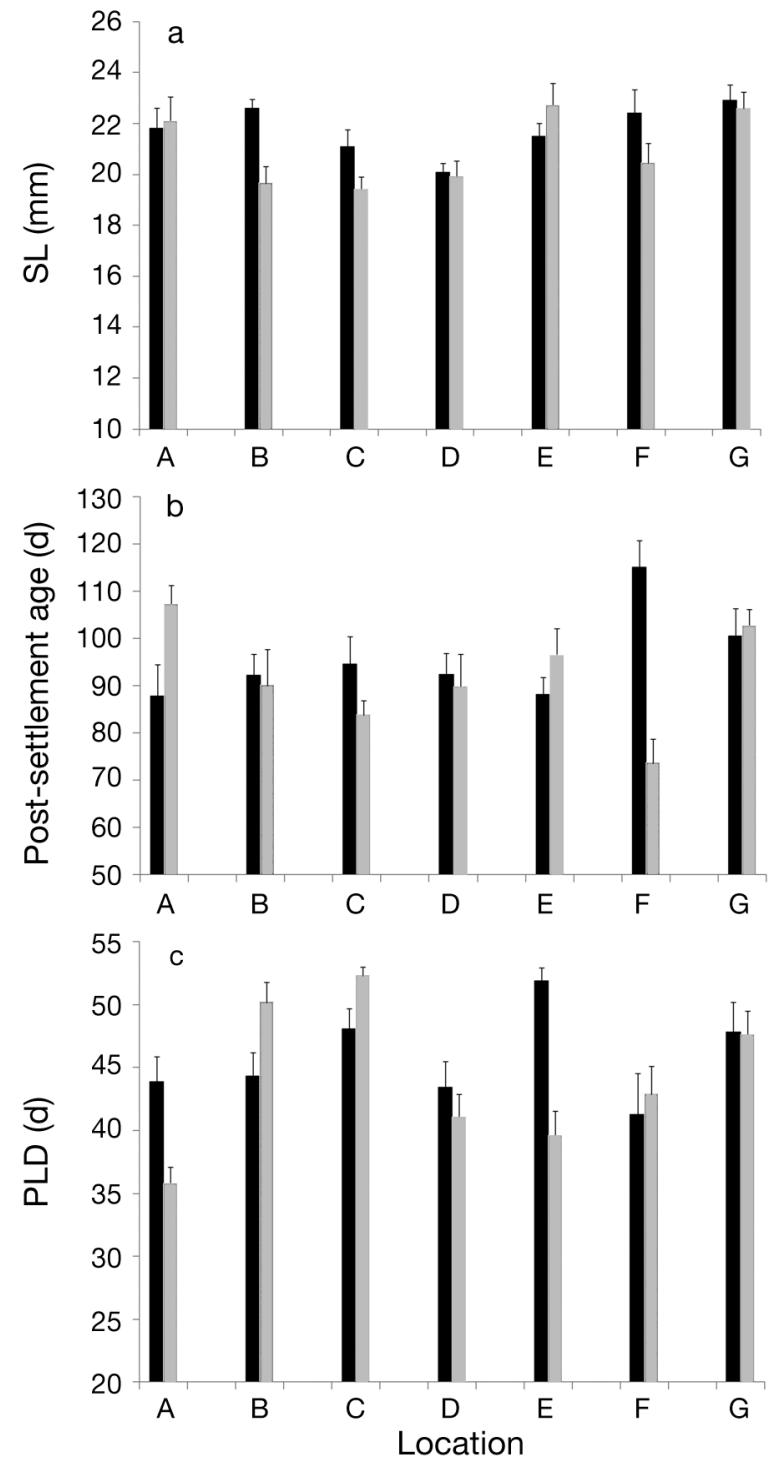

Fig. 2. (a) Standard length (SL) per site; (b) post-settlement age per site; c) pelagic larval duration (PLD) values per site. Data are mean \pm SD. Letters indicate locations, code see Fig. 1 legend. Black and grey bars indicate sites 1 and 2, respectively, in each location

No significant relationship ( $p>0.05$ ) was recorded between spawning date and PLD.

\section{DISCUSSION}

PLD and spawning dates of Diplodus vulgaris were significantly variable in space at the site level $(<6 \mathrm{~km})$, but not at the location level (15 to $30 \mathrm{~km})$. These outcomes are in line with the limited data reported by other studies carried out within and outside the Mediterranean Sea on other species (Di 


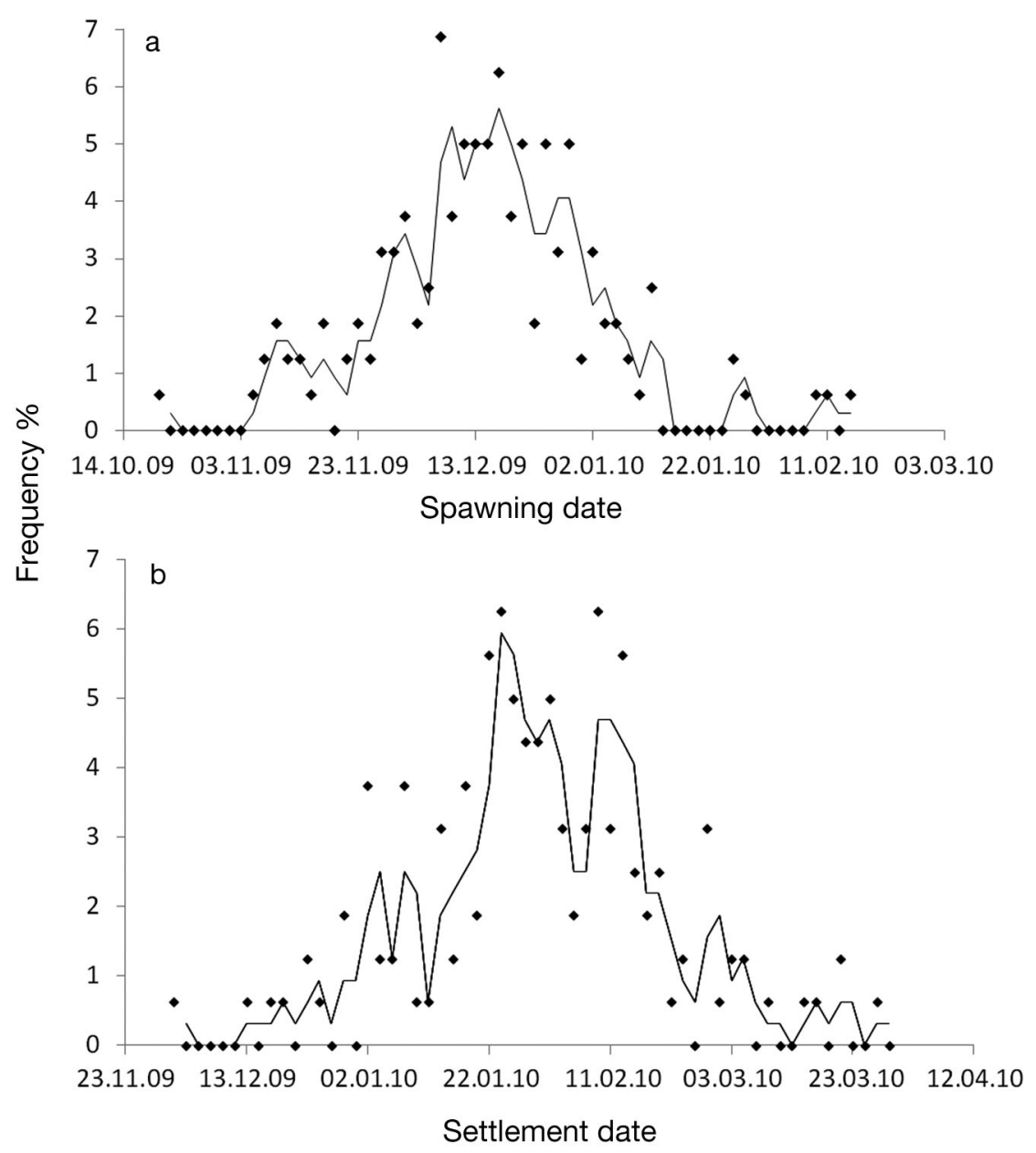

Fig. 3. Frequency chart for (a) spawning dates and (b) settling dates (dd. mm.yy). Frequency was calculated in intervals of $2 \mathrm{~d}$. Line $=$ moving average

within each location (separated up to $6 \mathrm{~km}$ ) could have been filled by different larval patches. Patch formation and maintenance may be due to behavior-mediated aggregation or passive accumulation (Paris \& Cowen 2004). The observed differences in ELTs could be explained either by small-scale variability in environmental and oceanographic features and processes (e.g. small areas of retention, coastal gyres, freshwater inputs) or in local differences of food availability and related growth conditions (Searcy \& Sponaugle 2000, Sponaugle et al. 2006, Vinagre et al. 2009). In particular, water temperature and food availability (that are sometime correlated, Fontes et al. 2010) may have the potential to affect larval history of fish, with warmer temperatures leading to faster growth (Sponaugle et al. 2006) and shorter larval duration (Sponaugle et al. 2006, Fontes et al. 2010). At present, however, these are just hypotheses and further studies could clarify what causal processes may actually have a predominant role in determining small scale variability patterns.

Different timing in larval arrival between sites close to each other could also be hypothesized in order to explain the patterns reported in

Franco \& Guidetti 2011, Kingsford et al. 2011), suggesting the idea that PLD and spawning dates can significantly vary at relatively small scales (e.g. few kilometers). No significant relationship among these 2 ELTs was highlighted at the individual level and spawning date does not influence larval duration at species level in the context of this work.

The significant variability detected in PLD and spawning date at a scale of a few kilometers could be an indication of local patchiness of larval pool at small spatial scales, as observed for other fish species (Paris \& Cowen 2004). Similar patterns suggest horizontal size estimates of larval patches that are usually restricted to a few kilometers (1 to 2 or $6 \mathrm{~km}$ depending on species and geographic area, Kingsford \& Choat 1989, Williams \& English 1992, Paris \& Cowen 2004). From this perspective, we could hypothesize that (based on our sampling design) sites the present study: sites could be 'filled up' by larval replenishment (i.e. habitat saturation), once filled they could not host more settlers, so that the next site (e.g. down-current with respect to larval source, Pelc et al. 2010) could then get filled with larvae born later

Table 1. ANCOVA on pelgic larval duration (PLD) and spawning dates. Standard length (SL) was set as covariate. Lo: location; Si: site; ns: not significant; Res: residuals; MS: mean squares. See text for factor labels. $\left.{ }^{* * *} p<0.001\right)$

\begin{tabular}{|lcccccc|}
\hline \multirow{2}{*}{ Source } & \multicolumn{4}{c}{ PLD } & \multicolumn{2}{c|}{ Spawning dates } \\
\cline { 2 - 5 } & df & MS & Pseudo-F & & MS & Pseudo-F \\
\hline SL & 1 & 157.71 & $1.5936 \mathrm{~ns}$ & 15468 & $51.335^{* * *}$ \\
Lo & 6 & 307.03 & $1.5162 \mathrm{~ns}$ & 200.15 & $0.20378 \mathrm{~ns}$ \\
Si (Lo) & 7 & 203.05 & $4.5134^{* * *}$ & 984.78 & $4.2015^{* * *}$ \\
Res & 145 & 44.988 & & & \\
Total & 159 & & & & \\
\hline
\end{tabular}




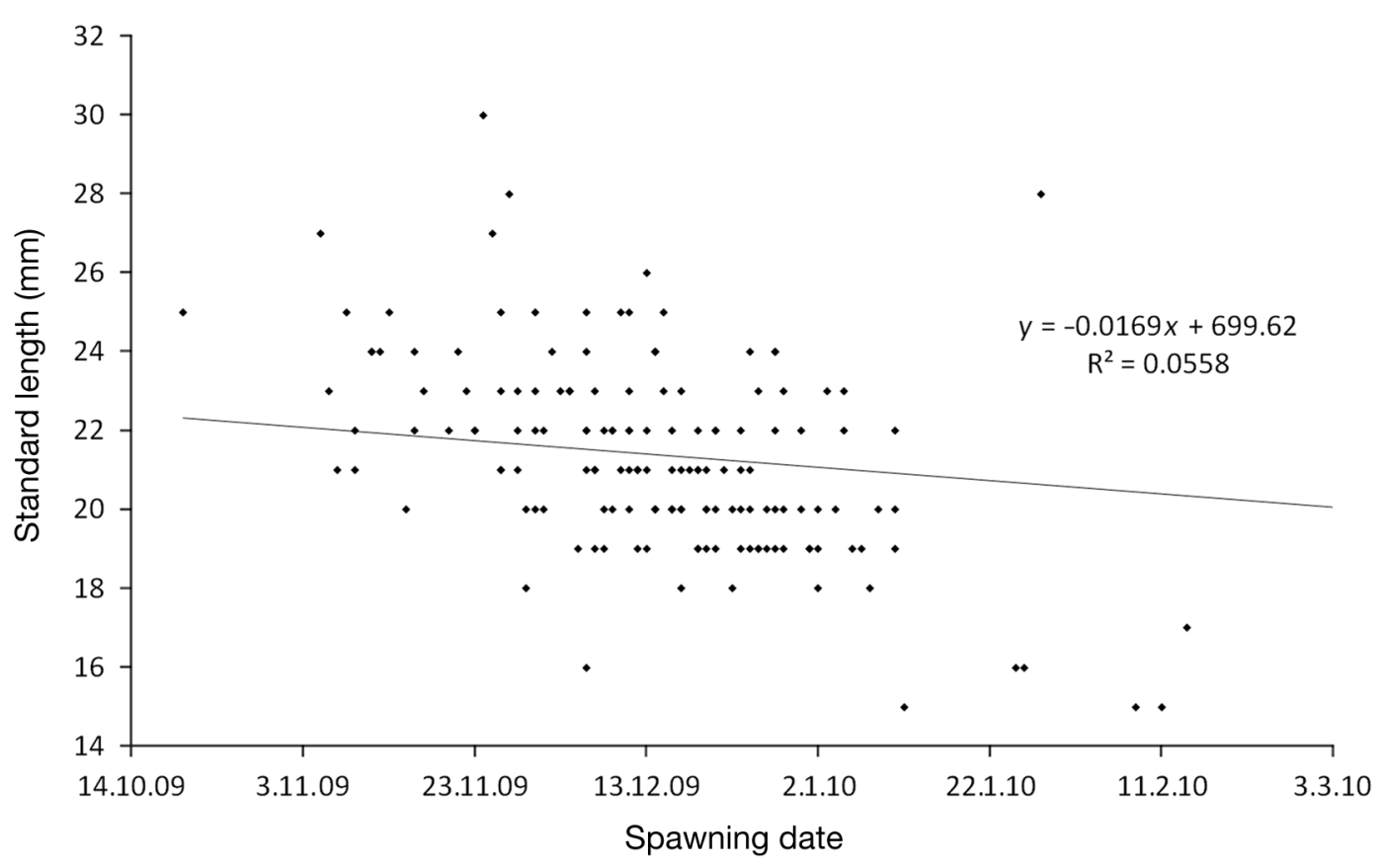

Fig. 4. Linear correlations of standard length (scale starts at $14 \mathrm{~mm}$ ) versus spawning date (i.e. calendar day, dd.mm.yy)

or with larvae delaying their metamorphosis (and then showing longer PLD). In addition to this potential effect of larval density, an effect of settler density could also affect PLD: in a site with low settler density, larvae could 'choose' to settle as soon as they can (which results in a short PLD) in order to minimize larval mortality, since the resulting small size at settlement could be further compensated by faster juvenile growth with reduced intraspecific competition (Fontes et al. 2010). On the other hand, at a higher settler density, settlement at a bigger size (resulting in a longer PLD, Denit \& Sponaugle 2004, Fontes et al. 2011) will increase the capability of escaping predators and successfully competing for shared resources (Tupper \& Boutilier 1995, McCormick 1999), despite having a higher larval mortality (Fontes et al. 2010). From this perspective, PLD could be the outcome of a trade-off among different pre-post settlement 'requirements' (Cowen \& Sponaugle 1997) aimed at maximizing chances of settling under optimal conditions (Sponaugle \& Cowen 1994).

Our findings refer to post-settlers which survived the early mortality phase. Early mortality rate has proven to be particularly high in reef fishes (Searcy \& Sponaugle 2001) and dependent on ELTs such as larval growth rates (Searcy \& Sponaugle 2001). Further, larval growth rate can influence PLD (Searcy and Sponaugle 2000). The ELTs reported here could no longer be fully representative of the original, recently settled juveniles or pre-settlement larvae due to postsettlement selective mortality. However, no information is available about selective early-mortality in two-banded sea bream and further studies are required to shed light on this issue.

We found an effect of fish size on spawning dates, indicating that larger juveniles were spawned earlier than smaller ones, thus demonstrating a relationship between juvenile size and total number of rings in the otoliths. Although this covariance may seem to be logically intuitive, it is not an invariable finding. Specifically, results from a previous study on Diplodus sargus (Di Franco \& Guidetti 2011) did not show any effect of fish SL on spawning dates, although this result may be due to the smaller fish size sampled in the previous study (mean $\pm \mathrm{SE}=11.1 \pm 0.1 \mathrm{~mm}$ ) compared to the present one $(25 \pm 0.2 \mathrm{~mm})$. These patterns could be explained by the absence of a positive relationship between PLD and size at settlement (Kingsford et al. 2011): when most of the rings in an otolith are pre-settlement rings (as in recently settled specimens, the ones considered in Di Franco \& Guidetti 2011), there is no evidence of a relationship between fish size and total number of rings (i.e. the sum of PLD and age in days after metamorphosis). This relationship is evident, on the contrary, when most of the rings in an otolith are post-settlement increments (as in the present study) due to the positive relationship in juvenile fish between size and 
age (see Gordoa \& Molì 1997 for further details). Growth rates at the larval stage can be highly variable among larvae that experience different environmental conditions (i.e. variable in time) due to a prolonged spawning (and hatching) period. Successively, growth rates of juveniles after settlement may become less variable, progressively smoothing the differences and providing a positive relationship between fish size and number of rings. The relationship among fish size and spawning date, therefore, could be mainly affected by the timing of the sampling rather than by bio-ecological features.

Variation in PLD has already been reported for Diplodus vulgaris from the NW Mediterranean (Vigliola 1998), with an average $40 \mathrm{~d}$ PLD (minimum of $29 \mathrm{~d}$ and maximum of $58 \mathrm{~d}$ ), that is lower than PLD found in the present study in SE Italy. Unfortunately, we cannot identify the source of this difference in PLD between these 2 studies (e.g. in terms of spatial or temporal effects) due to different sampling years (1995 and 1996 versus 2010) and locations (NW Mediterranean Sea versus SW Adriatic Sea). This suggests the need to conduct similar studies in different locations and across a number of years in order to allow reliable comparisons. As discussed above, spatial or temporal variability in PLD is likely due to differential growth rates at the larval stage related to variability in environmental conditions. This hypothesis is supported by the evidence of variability in growth rates at the juvenile stage for the two-banded sea bream recorded in NW Mediterranean (Planes et al. 2000).

In our study on Diplodus vulgaris we detected the settlement peak around January and February, agreeing with references in the literature (Biagi et. al 1998, Vigliola et al. 1998). However, a second peak between April and May was not observed, different from what has been reported in other papers (García Rubies \& Macpherson 1995, Bussotti \& Guidetti 2011). This discrepancy could be due to the fact that our sampling (carried out in May) could have been done when the 'spring' settlement peak had just started (especially in the case of a delayed event; Bussotti \& Guidetti 2011). However, no evidence of any additional settlement peak was actually observed in the same area and year investigated by us. This could suggest that, depending on the year, 1 or 2 settlement events could take place.

From spawning dates, the range from October to February indicates that Diplodus vulgaris has an extended spawning period. This result agrees with the evidence arising from gonad maturation assessments of $D$. vulgaris from the same sampling area
(Guidetti et al. 2011) and more generally, from other sites along the Italian coast (ranging from September to November, Barbato \& Corbari 1995). In other areas (e.g. Canarian archipelago and Portuguese coast, both in the Atlantic Ocean), winter spawning season is protracted (November to March, Pajuelo et al. 2006; December to March, Gonçalves \& Erzini 2000), while a longer spawning season has been reported from Portugal (from September to March, Gonçalves et al. 2003).

Patterns of dispersal and connectivity are likely to vary greatly depending on spatio-temporal variability of factors driving connectivity (i.e. spawning date, PLD, water circulation regimes, that may change annually, seasonally, spatially; Astraldi et al. 1995, Siegel et al. 2008, Schunter et al. 2011), which may greatly affect the outputs of connectivity or dispersal models (Siegel et al. 2008, Watson et al. 2010). From this perspective the outcomes of our investigation suggest that values of PLD and spawning dates may show specific patterns of variability that may change in space and likely in time (e.g. from year to year). This should be taken into account when modeling dispersal and connectivity for Diplodus vulgaris, but the rationale is the same for any other fish species: it could be valuable to acknowledge the potential spatial and temporal variability of ELTs and not to treat them as constant values, invariable in space and time as it has been done in many previous studies.

Acknowledgements. This study has been done in the framework of the project entitled 'Designing networks of marine protected areas in the Mediterranean context', funded by Total Foundation. Many thanks are due to the 3 anonymous reviewers for critically commenting on the manuscript.

\section{LITERATURE CITED}

Almany GR, Connolly SR, Heath D, Hogan JD and others (2009) Connectivity, biodiversity conservation and the design of marine reserve networks for coral reefs. Coral Reefs 28:339-351

Anderson MJ, Gorley RN, Clarke KR (2008) PERMANOVA+ for PRIMER: guide to software and statistical methods. PRIMER-E, Plymouth

Astraldi M, Bianchi CN, Gasparini GP, Morri C (1995) Climatic fluctuations, current variability and marine species distribution: a case study in the Ligurian Sea (north-west Mediterranean). Oceanol Acta 18:139-149

Barbato F, Corbari L (1995) New species in Italy. Aspects économiques de la production aquacole (Aquaculture production economics) Zaragoza: Seminar of the CIHEAM Network on Socio-economic and Legal Aspects of Aquaculture in the Mediterranean (SELAM), 1995/05/17-19, Montpellier (France). Cahiers Options Méditerranéennes (CIHEAM-IAMZ, 1995) 14:123-128 
Bauchot ML, Hureau JC (1986) Sparidae. In: Whitehead PJP, Bauchot ML, Hureau JC, Nielson J, Tortonese E (eds) Fishes of the North-eastern Atlantic and the Mediterranean, Vol II. UNESCO, Paris, p 883-907

> Biagi F, Gambaccini S, Zazzetta M (1998) Settlement and recruitment in fishes: the role of coastal areas. Ital J Zool 65:269-274

Bussotti S, Guidetti P (2011) Timing and habitat preferences for settlement of juvenile fishes in the Marine Protected Area of Torre Guaceto (south-eastern Italy, Adriatic Sea). Ital J Zool 78:243-254

Cowen RK, Sponaugle S (1997) Relationships between early life history traits and recruitment in coral reef fishes. In: Chambers RC, Trippel E (eds) Early life history and recruitment in fish populations. Chapman \& Hall, London, p 423-449.

> Denit K, Sponaugle S (2004) Growth variation, settlement and spawning of the gray snapper Lutjanus griseus across a latitudinal gradient. Trans Am Fish Soc 133: 1339-1355

Di Franco A, Guidetti P (2011) Patterns of variability in early-life traits of fishes (Diplodus sargus sargus) depend on spatial scale of analysis. Biol Lett 7:454-456

Di Franco A, De Benedetto G, De Rinaldis G, Raventos N, Sahyoun R, Guidetti P (2011) Large scale-variability in otolith microstructure and microchemistry: the case study of Diplodus sargus sargus (Pisces: Sparidae) in the Mediterranean Sea. Ital J Zool 78:182-192

Fontes J, Afonso P, Santos SR, Caselle JE (2010) Temporal variability of larval growth, size, stage duration and recruitment of a wrasse, Coris julis (Pisces: Labridae), from the Azores. Sci Mar 74:721-729

> Fontes J, Santos SR, Afonso P, Caselle JE (2011) Larval growth, size, stage duration and recruitment success of a temperate reef fish. J Sea Res 65:1-7

- García-Rubies A, Macpherson E (1995) Substrate use and temporal pattern of recruitment in juvenile fishes of the Mediterranean littoral. Mar Biol 124:35-42

Gonçalves JMS, Erzini K (2000) The reproductive biology of the two banded sea bream Diplodus vulgaris from the southwest coast of Portugal. J Appl Ichthyology 16: 110-116

> Gonçalves JMS, Bentes L, Coelho R, Correia C and others (2003) Age and growth, maturity, mortality and yieldper-recruit for two banded bream (Diplodus vulgaris Geoffr.) from the south coast of Portugal. Fish Res 62: 349-359

> Gordoa A, Molì A (1997) Age and growth of the sparids Diplodus vulgaris, D. sargus and D. annularis in adult populations and the differences in their juvenile growth patterns in the north-western Mediterranean Sea. Fish Res 33:123-129

Green BS, Mapstone B, Carlos G, Begg GA (2009) Tropical fish otoliths: information for assessment, management and ecology. Springer, New York, NY

> Guidetti P (2006) Marine reserves re-establish lost predatory interactions and cause community-wide changes in rocky reefs. Ecol Appl 16:963-976

Guidetti P, Bussotti S, Calò A, Di Franco A and others (2011) Reproductive patterns and early life-history traits of the two-banded sea bream (Diplodus vulgaris, Geoffroy Saint-Hilaire, 1817) at the Marine Protected Area of Torre Guaceto (SW Adriatic, Italy): implications for management and conservation. Proc 2011 Congr Soc Zool France, Nice
Hamilton SL, Regetz J, Warner RR (2008) Postsettlement survival linked to larval life in a marine fish. Proc Natl Acad Sci USA 105:1561-1566

> Harmelin-Vivien ML, Harmelin JG, Lebolleux V (1995) Microhabitat requirements for settlement of juvenile sparid fishes on Mediterranean rocky shores. Hydrobiologia 300-301:309-320

Jones GP, Almany GR, Russ GR, Sale PF, Steneck RS, van Oppen MJH, Willis BL (2009) Larval retention and connectivity among populations of corals and reef fishes: history, advances and challenges. Coral Reefs 28: 307-325

> Jug-Dujakovic J, Glamuzina B (1988) Preliminary studies of reproduction and early life history of Diplodus vulgaris (E. Geoffroy Saint-Hilaire 1817) in captivity. Aquaculture 69:367-377

Kettle AJ, Haines K (2006) How does the European eel (Anguilla anguilla) retain its population structure during its larval migration across the North Atlantic Ocean? Can J Fish Aquat Sci 63:90-106

Kingsford MJ, Choat JH (1989) Horizontal distribution patterns of presettlement reef fish: Are they influenced by the proximity of reefs? Mar Biol 101:285-297

Kingsford MJ, Smith FJA, Flood MJ (2011) Growth and pelagic larval duration of presettlement and newly settled neon damselfish, Pomacentrus coelestis, at multiple spatial scales. Coral Reefs 30:203-214

> Leggett WC, DeBlois E (1994) Recruitment in marine fishes: Is it regulated by starvation and predation in the egg and larval stages. Neth J Sea Res 32:119-134

> Lloret J, Zaragoza N, Caballero D, Riera V (2008) Biological and socioeconomic implications of recreational boat fishing for the management of fishery resources in the marine reserve of Cap de Creus (NW Mediterranean). Fish Res 91:252-259

McCook LJ, Almany GR, Berumen ML, Day JC and others (2009) Management under uncertainty: guide-lines for incorporating connectivity into the protection of coral reefs. Coral Reefs 28:353-366

- McCormick MI (1999) Delayed metamorphosis of a tropical reef fish (Acanthurus triostegus): a field experiment. Mar Ecol Prog Ser 176:25-38

> Pajuelo JG, Lorenzo JM, Bilbao A, Ayza O, Ramos AG (2006) Reproductive characteristics of the benthic coastal fish Diplodus vulgaris (Teleostei: Sparidae) in the Canarian archipelago, northwest Africa. J Appl Ichthyology 22: 414-418

> Palumbi SR (2003) Population genetics, demographic connectivity, and the design of marine reserves. Ecol Appl 13:146-158

Panfili J, de Pontual H, Troadec H, Wright PJ (2002) Manual of fish sclerochronology. Ifremer-IRD, Brest

Pannella G (1971) Fish otoliths: daily growth layers and periodical patterns. Science 173:1124-1127

> Paris CB, Cowen RK (2004) Direct evidence of a biophysical retention mechanism for coral reef fish larvae. Limnol Oceanogr 49:1964-1979

> Pelc RA, Warner RR, Gaines S, Paris CB (2010) Detecting larval export from marine reserves. Proc Natl Acad Sci USA 107:18266-18271

> Philibotte J (2002) Pelagic larval duration of the Caribbean wrasse, Thalassoma bifasciatum. Biol Bull 203:245-246

> Planes S, Galzin R, García Rubies A, Goni R and others (2000) Effects of marine protected areas on recruitment processes with special reference to Mediterranean lit- 
toral ecosystems. Environ Conserv 27:126-143

Saenz-Agudelo P, Jones GP, Thorrold SR, Planes S (2011) Connectivity dominates larval replenishment in a coastal reef fish metapopulation. Proc R Soc Lond B 278: 2954-2961

Sale PF, Cowen RK, Danilowicz BS, Jones GP and others (2005) Critical science gaps impede use of no-take fishery reserves. Trends Ecol Evol 20:74-80

Schunter C, Carreras-Carbonell J, Macpherson E, Tintoré J and others (2011) Matching genetics with oceanography: directional gene flow in a Mediterranean fish species. Mol Ecol 20:5167-5181

Searcy SP, Sponaugle S (2000) Variable larval growth in a coral reef fish. Mar Ecol Prog Ser 206:213-226

Searcy SP, Sponaugle S (2001) Selective mortality during the larval-juvenile transition in 2 coral reef fishes. Ecology 82:2452-2470

Siegel DA, Kinlan BP, Gaylord B, Gaines SD (2003) Lagrangian descriptions of marine larval dispersion. Mar Ecol Prog Ser 260:83-96

Siegel DA, Mitarai S, Costello CJ, Gaines SD, Kendall BE, Warner RR, Winters KB (2008) The stochastic nature of larval connectivity among nearshore marine populations. Proc Natl Acad Sci USA 105:8974-8979

Sponaugle S, Cowen RK (1994) Larval durations and recruitment patterns of 2 Caribbean gobies (Gobiidae): contrasting early life histories in demersal spawners. Mar Biol 120:133-143

Sponaugle S, Grorud-Colvert K, Pinkard D (2006) Temperature-mediated variation in early life history traits and recruitment success of the coral reef fish Thalassoma bifasciatum in the Florida Keys. Mar Ecol Prog Ser 308: $1-15$

Thresher RE, Colin PL, Bell LJ (1989) Planktonic duration, distribution and population structure of western and central Pacific damselfishes (Pomacentridae). Copeia 1989: 420-434

Tsuji S, Aoyama T (1982) Daily growth increments observed in otoliths of the larvae of Japanese red sea bream Pagrus major (Temminch et Schlegel). Bull Jpn Soc Sci Fish 48:1559-1562

Tupper M, Boutilier RG (1995) Size and priority at settlement determine growth and competitive success of newly settled Atlantic cod. Mar Ecol Prog Ser 118:295-300

Victor BC (1982) Daily otolith increments and recruitment in 2 coral reef wrasses, Thalassoma bjfasciatum and Hali-

Editorial responsibility: Stylianos Somarakis, Heraklion, Crete, Greece choeres bivittatus. Mar Biol 71:203-208

Vigliola L (1997) Validation of daily increment formation in otoliths for 3 Diplodus species in the Mediterranean Sea. J Fish Biol 51:349-360

Vigliola L (1998) Contrôle et régulation du recruitment des sparidae (Poissons, Téléostéens) en Méditerranée: importance des processus pré- et post-installation benthique. PhD thesis, University Aix-Marseille II

Vigliola L, Meekan MG (2002) Size at hatching and planktonic growth determine post-settlement survivorship of a coral reef fish. Oecologia 131:89-93

- Vigliola L, Harmelin-Vivien ML, Biagi F, Galzin R and others (1998) Spatial and temporal patterns of settlement among sparid fishes of the genus Diplodus in the northwestern Mediterranean. Mar Ecol Prog Ser 168:45-56

Vigliola L, Harmelin-Vivien M, Meekan MG (2000) Comparison of techniques of back-calculation of growth and settlement marks from the otoliths of 3 species of Diplodus from the Mediterranean Sea. Can J Fish Aquat Sci 57:1291-1299

Villanueva R, Moli B (1997) Validation of the otolith increment deposition ratio using alizarin marks in juveniles of the sparid fishes, Diplodus vulgaris and D. puntazzo. Fish Res 30:257-260

> Vinagre C, Ferreira T, Matos L, Costa MJ, Cabral HN (2009) Latitudinal gradients in growth and spawning of sea bass, Dicentrarchus labrax, and their relationship with temperature and photoperiod. Estuar Coast Shelf Sci 81: 375-380

> Watson JR, Mitarai S, Siegel DA, Caselle JE, Dong C, McWilliams JC (2010) Realized and potential larval connectivity in the Southern California Bight. Mar Ecol Prog Ser 401:31-48

Werner FE, Cowen RK, Paris CB (2007) Coupled biological and physical models present capabilities and necessary developments for future studies of population connectivity. Oceanography 20:54-69

Williams DM (1983) Daily, monthly and yearly variability in recruitment of a guild of coral reef fishes. Mar Ecol Prog Ser 10:231-237

- Williams DM, English S (1992) Distribution of fish larvae around a coral reef: direct detection of a meso-scale, multi-specific patch. Cont Shelf Res 12:923-937

Wilson DT, McCormick MI (1997) Spatial and temporal validation of settlement-marks in the otoliths of tropical reef fishes. Mar Ecol Prog Ser 153:259-271

Submitted: June 12, 2012; Accepted: October 12, 2012

Proofs received from author(s): February 11, 2013 